\title{
OPEN Metabolic and enzymatic elucidation of cooperative degradation of red seaweed agarose by two human gut bacteria
}

\author{
Eun JuYun ${ }^{1,2}$, Sora Yu ${ }^{1}$, Na Jung Park ${ }^{1}$, Yoonho $\mathrm{Cho}^{1}$, Na Ree Han ${ }^{1}$, Yong-Su Jin ${ }^{2,3 \otimes}$ \& \\ Kyoung Heon $\mathrm{Kim}^{1 \otimes}$
}

Various health beneficial outcomes associated with red seaweeds, especially their polysaccharides, have been claimed, but the molecular pathway of how red seaweed polysaccharides are degraded and utilized by cooperative actions of human gut bacteria has not been elucidated. Here, we investigated the enzymatic and metabolic cooperation between two human gut symbionts, Bacteroides plebeius and Bifidobacterium longum ssp. infantis, with regard to the degradation of agarose, the main carbohydrate of red seaweed. More specifically, B. plebeius initially decomposed agarose into agarotriose by the actions of the enzymes belonging to glycoside hydrolase (GH) families 16 and 117 (i.e., $B p G H 16 \mathrm{~A}$ and $B p G H 117$ ) located in the polysaccharide utilization locus, a specific gene cluster for red seaweed carbohydrates. Then, $B$. infantis extracted energy from agarotriose by the actions of two agarolytic $\beta$-galactosidases (i.e., Bga42A and $\mathrm{Bga} 2 \mathrm{~A}$ ) and produced neoagarobiose. $B$. plebeius ultimately acted on neoagarobiose by $B p G H 117$, resulting in the production of 3,6-anhydro-Lgalactose, a monomeric sugar possessing anti-inflammatory activity. Our discovery of the cooperative actions of the two human gut symbionts on agarose degradation and the identification of the related enzyme genes and metabolic intermediates generated during the metabolic processes provide a molecular basis for agarose degradation by gut bacteria.

One of the crucial roles of the gut microbiota is to extract energy and nutrients from dietary polysaccharides using Carbohydrate-Active enZymes (CAZymes) that are not expressed by the human body ${ }^{1-3}$. Various oligosaccharides generated from the degradation of dietary polysaccharides by gut bacteria markedly impact the health and gut physiology of the host by modulating the composition of the gut microbiota ${ }^{4}$. Two phyla-Bacteroidetes and Firmicutes-dominate the bacterial community of the adult distal gut ${ }^{5}$. In particular, members of the genus Bacteroides are broadly involved in degrading host glycans $s^{6,7}$ and terrestrial plant polysaccharides in the gut ${ }^{1,2,4,8}$. For example, Bacteroides thetaiotaomicron-a prominent human gut symbiont-contains a huge repertoire of glycoside hydrolases (GHs) and polysaccharide lyases for degrading dietary polysaccharides derived from plants, such as starch, pectin, and hemicellulose ${ }^{1,4,9}$. Most studies regarding the degradation pathways and roles of dietary polysaccharides in human and animal guts have focused on polysaccharides derived from terrestrial plants ${ }^{2,8,10}$. However, the degradation pathways of dietary seaweeds in the gut and the potential roles of oligosaccharides and rare sugars generated after the consumption of seaweeds have rarely been studied to date $e^{3,11,12}$.

In East Asia including Japan, Korea, and China, people frequently consume red or brown seaweeds, such as agar, nori, kombu, and wakame ${ }^{13}$. These seaweeds have potential therapeutic or preventative effects against various diseases and health concerns such as Type 2 diabetes $^{14}$, obesity ${ }^{15}$, cardiovascular disease mortality ${ }^{16}$, and hypocholesterolaemic effect ${ }^{17}$. Because the major components of seaweeds are polysaccharides ${ }^{18,19}$, it is likely that the health benefits of seaweed diet may be attributed to the polysaccharides. For example, fucoidan, one of the major polysaccharides of brown seaweeds, is widely known to be the key for the anticancer activity of brown seaweeds ${ }^{20-23}$. With regard to the health benefits of red seaweeds, 3,6-anhydro-L-galactose (AHG), the monomeric sugar of agar along with galactose, was reported to exhibit strong in vitro anti-inflammatory activity, indicating the significant suppression of nitrite production in our previous study ${ }^{24}$. Therefore, we reasoned that AHG may

${ }^{1}$ Department of Biotechnology, Graduate School, Korea University, Seoul 02841, Republic of Korea. ${ }^{2}$ Carl R. Woese Institute for Genomic Biology, University of Illinois at Urbana-Champaign, Urbana, IL 61801, USA. ${ }^{3}$ Department of Food Science and Human Nutrition, University of Illinois at Urbana-Champaign, Urbana, IL 61801, USA. ${ }^{\square}$ email: ysjin@illinois.edu; khekim@korea.ac.kr 
have been responsible for the beneficial effects of dietary red seaweeds reported in previous clinical trials and epidemiological studies ${ }^{25-27}$. However, it is debatable if and how AHG is released in the human gastrointestinal tract after red seaweeds are ingested. Agar is the major component of red seaweeds, and is mainly composed of agarose, which is the linear polysaccharide of AHG and D-galactose joined alternately by $\alpha-1,3-$ and $\beta-1,4-$ glycosidic linkages ${ }^{28}$. Because agar cannot be degraded by human GHs, the degradation and metabolic pathways of agar in the human gut may rely on microbial GHs.

The CAZymes of only two human gut bacteria-namely Bacteroides plebeius DSM 17135 and Bacteroides uniformis NP1-have been reported to degrade agar ${ }^{11,29}$. Specifically, B. plebeius was isolated from the guts of seaweed-eating Japanese people and was found to possess CAZymes that act on red seaweed polysaccharides including porphyran (highly sulfated and methylated agarose) ${ }^{30}$ and agarose (non-sulfated agarose) (Fig. 1A) ${ }^{3,29}$. In particular, the CAZymes of $B$. plebeius are capable of degrading agarose ${ }^{3,29,31}$, the main polysaccharide of agar (Fig. 1A). However, B. plebeius is incapable of completely degrading and utilizing agarose as a carbon source, probably owing to the incompleteness of its agarose degradation system ${ }^{29}$. Therefore, agarose degradation in the human gut cannot be fully attributed to the agar-degrading enzymes of B. plebeius alone. As such, for dietary agarose to be further degraded into its monomeric sugars (AHG and galactose) in the human gut, other human gut bacteria must cooperate with $B$. plebeius. In this study, we have designed a model system consisting of agarose with $B$. plebeius together with a well-known human gut bacterium Bifidobacterium longum ssp. infantis ATCC 15697 that may be capable of cooperating in the degradation of agarose. Using this cooperative model system, the polysaccharide degradation pathway for red seaweed agarose by the possible human gut symbionts is provided.

\section{Results}

Agarose degradation profiles of B. plebeius. First, we cultured B. plebeius in a modified minimal broth $^{29}$ supplemented with $5 \mathrm{~g} / \mathrm{L}(\mathrm{w} / \mathrm{v})$ agarose pretreated by a simulated gastric fluid for $2 \mathrm{~h}$. We found that during the fermentation of $B$. plebeius with the pretreated agarose, agarotriose (AgaDP3; an agarooligosaccharide with a degree of polymerization (DP) of 3, composed of D-galactose, AHG, and D-galactose joined by $\beta$ - 1,4 - and $\alpha-1,3$-glycosidic linkages) was produced as the main fermentation product (Fig. 1B). The AgaDP3 generated by $B$. plebeius was identified by liquid chromatography/mass spectrometry hybrid ion trap time-of-flight (LC/ MS - IT - TOF) analysis of the culture supernatant of B. plebeius grown on agarose (Fig. 1E).

Next, we investigated the agarose degradation pathway of $B$. plebeius - which leads to the accumulation of AgaDP3 from agarose-using in vitro reactions of crude enzymes obtained from $B$. plebeius grown with the pretreated agarose. The crude enzymes were divided into a fraction containing extracellular enzymes, and a cellfree lysate containing intracellular and membrane-associated enzymes. Initially, we mainly observed endo-type $\beta$-agarase activity in the fraction with extracellular enzymes (Supplementary Fig. 1A-C). The major reaction product with the extracellular enzymes was identified as neoagarotetraose (NeoDP4; an agarooligosaccharide with a DP of 4, composed of AHG, D-galactose, AHG, and D-galactose joined by alternating $\alpha-1,3-$ and $\beta$-1,4glycosidic linkages) by LC/MS - IT - TOF analysis (Fig. 1F). The absence of neoagarobiose (NeoDP2; a disaccharide composed of AHG and D-galactose joined by an $\alpha$-1,3-glycosidic linkage) in the reaction product of agarose with the extracellular enzymes indicated that exo-type $\beta$-agarase activity producing NeoDP2 did not occur in the extracellular enzyme fraction (Supplementary Fig. 1A-C). The intracellular enzyme fraction exhibited neoagarobiose hydrolase (NABH) activity, releasing AHG from NeoDP2 by cleavage of the $\alpha$-1,3-glycosidic bond of NeoDP2 (Supplementary Fig. 2A-C). Finally, we confirmed AgaDP3 production resulting from the degradation of agarose by $B$. plebeius by the sequential reactions of the extracellular and intracellular enzymes of $B$. plebeius: agarose was initially depolymerized into NeoDP4 by the extracellular enzymes, and NeoDP4 was then hydrolyzed into AgaDP3 and AHG by the intracellular enzymes (Fig. 1C,D).

Agarose-degrading enzymes in B. plebeius. The polysaccharide utilization locus (PUL) of B. plebeius contains CAZymes, which are active on algal polysaccharides including porphyran (highly sulfated and methylated agarose) and agarose (non-sulfated agarose) ${ }^{29,31}$. In the PUL of B. plebeius, the genes encoding enzymes belonging to $\mathrm{GH}$ families 16, 50, and 117 (i.e., BpGH16A, BpGH50, and BpGH117) are related to agarose degradation pathway via the $\beta$-agarase system. Among these enzymes, $B p \mathrm{GH} 16 \mathrm{~A}$ and $B p \mathrm{GH} 117$ were biochemically characterized in the previous studies ${ }^{29,31,32}$. Here, we elucidated the combination and reaction sequence of enzymes leading to produce AgaDP3 and AHG from agarose, as we observed in the fermentation profiles of $B$. plebeius in the presence of agarose (Fig. 1B) and in vitro reactions using the crude enzymes of B. plebeius on agarose (Fig. 1C,D).

After obtaining BpGH16A, BpGH50, and BpGH117 via recombinant protein expression and purification of each (Fig. 2B), we performed the enzymatic reactions in vitro (Fig. 2C). First, we confirmed the activity of $B p \mathrm{GH} 16 \mathrm{~A}$ on agarose substrate. As previously reported, the major reaction product of $B p \mathrm{GH} 16 \mathrm{~A}$ with agarose was NeoDP4 (Fig. 2C) ${ }^{32}$, which was identified by combining the results of thin-layer chromatography (TLC) and LC/MS - IT - TOF analyses of the reaction products of BpGH16A (Figs. $1 \mathrm{~F}$ and $2 \mathrm{C}$ ).

Second, we attempted to determine the activity of $B p$ GH50, which possibly takes part in the next step of the agarose degradation pathway by degrading neoagarooligosaccharides (NAOSs; agarooligosaccharides with AHG on the non-reducing end) into NeoDP2. As previously reported ${ }^{33}, B p \mathrm{GH} 50$ did not exhibit an exo-type $\beta$-agarase activity producing NeoDP2 toward agarose (Fig. 2C). Moreover, we found that BpGH50 did not exhibit activity on NeoDP4, the major product produced by BpGH16A reaction with agarose (Supplementary Fig. 3). Finally, we confirmed the activity of $B p \mathrm{GH} 117$, which is known to recognize AHG at the non-reducing end of NAOSs including NeoDP2 and produce $\mathrm{AHG}^{31}$, by TLC analysis of the reaction products of BpGH117 (Fig. 2C). In summary, of the three enzymes related to the agarose degradation pathway, we found that only $B p \mathrm{GH} 16 \mathrm{~A}$ and Bp GH117 participated in the agarose degradation (Fig. 2C). 


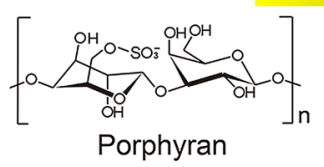

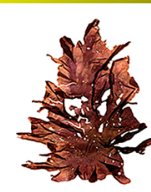

Porphyra

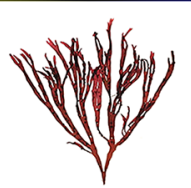

Gracilaria

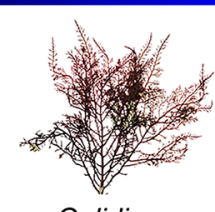

Gelidium

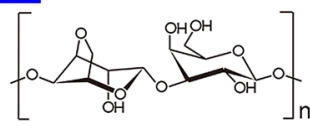

Agarose

( 55 wt $\%$ of dry G. amansii $\left.{ }^{\text {a }}\right)$

(e.g. Gelidium amansii)
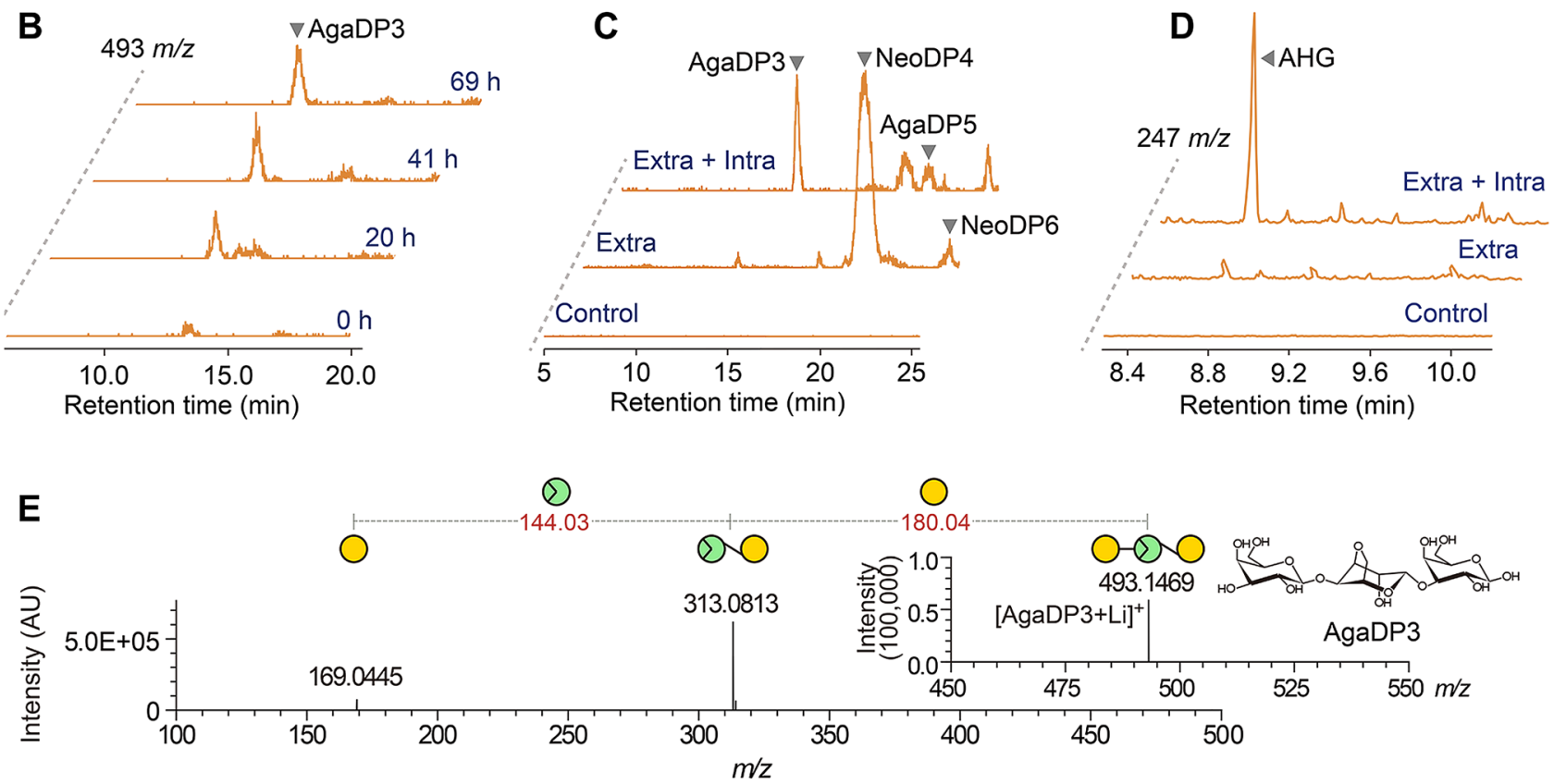

$\mathbf{F}$
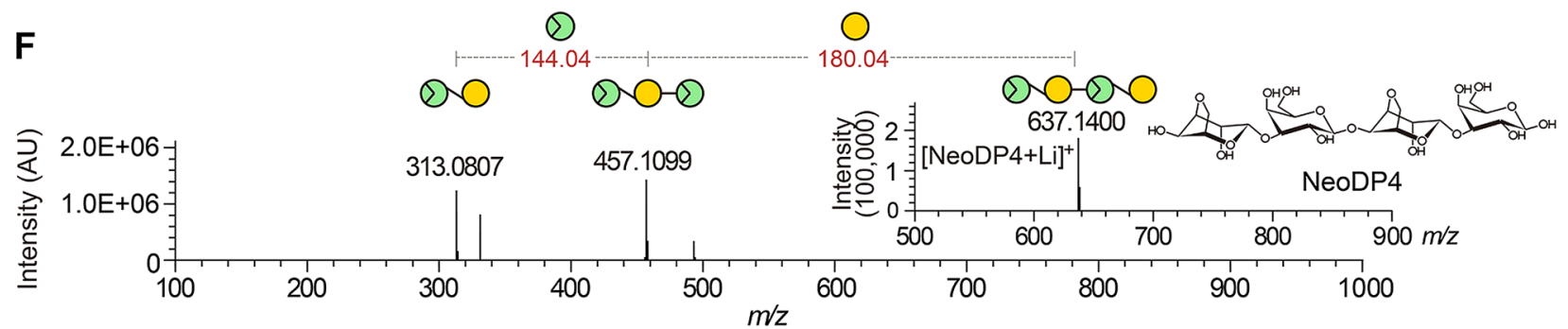

Figure 1. Agarose degradation profiles of B. plebeius. (A) Galactan structures found in various species of agarophytic red seaweeds (e.g., those from the genera Porphyra, Gracilaria, and Gelidium). Porphyran and agarose are the major carbohydrate components of red seaweeds. L-Galactose-6-sulfate and D-galactose are the monomeric constituents of porphyran, and AHG and D-galactose are the monomeric constituents of agarose. The main cell wall carbohydrates of species of the genera Porphyra and Gelidium are porphyran and agarose, respectively. Specifically, the main cell wall carbohydrate in red macroalgae (e.g., Gelidium amansii) is agar, which consists of agarose and agaropectin. (B) Profiles of agarose degradation by B. plebeius. During the fermentation of pretreated agarose by B. plebeius, AgaDP3 - a trisaccharide composed of D-galactose and AHG - was produced as the main degradation product of agarose. We analyzed the AgaDP3 in the culture supernatant of B. plebeius by LC/MS - IT - TOF at $493 \mathrm{~m} / z$. (C and D) Analyses of the reaction products obtained from the sequential enzymatic reactions using extracellular crude enzymes (Extra in C and D) and cell free lysate containing intracellular and membrane-associated enzymes (Intra in C and D) of B. plebeius with agarose as the substrate. The AOSs and NAOSs were analyzed by LC/MS - IT - TOF (C), and the AHG produced by the enzymatic reactions was analyzed by GC-MS at $247 \mathrm{~m} / z$ (D). (E and F) Identification of AgaDP3 and NeoDP4 using LC/MS - IT - TOF. Tandem mass spectra of AgaDP3 (E) and NeoDP4 (F). The inset figures of E and $\mathrm{F}$ show the mass spectra of AgaDP3 and NeoDP4, respectively. 
A

Polysaccharide utilization locus in Bacteroides plebeius

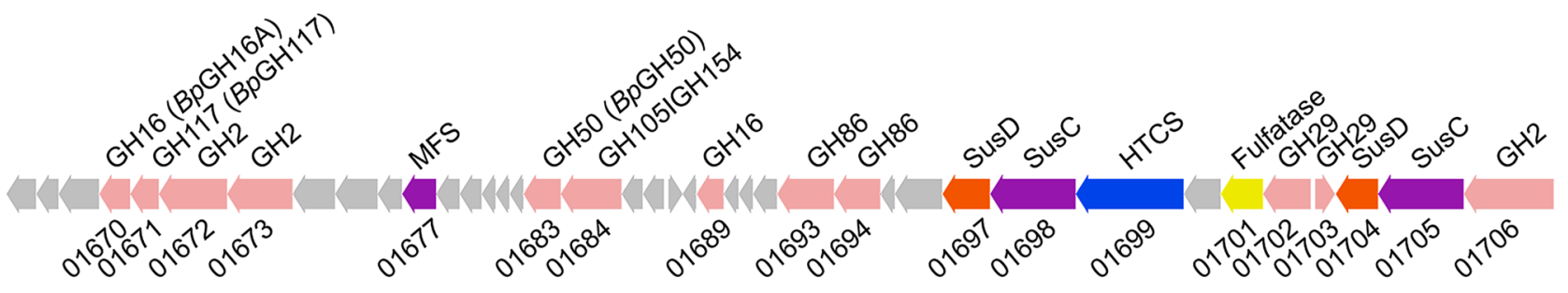

B

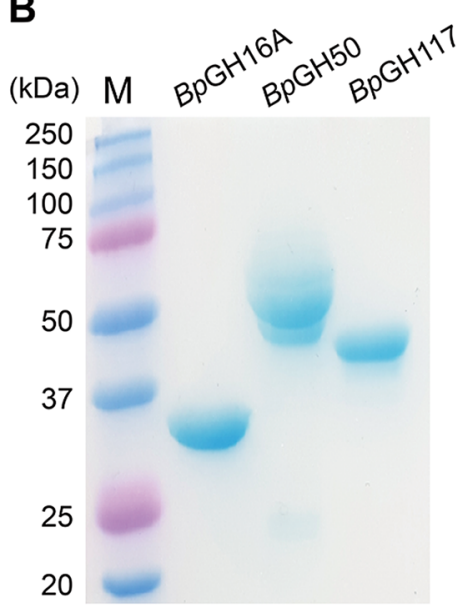

E

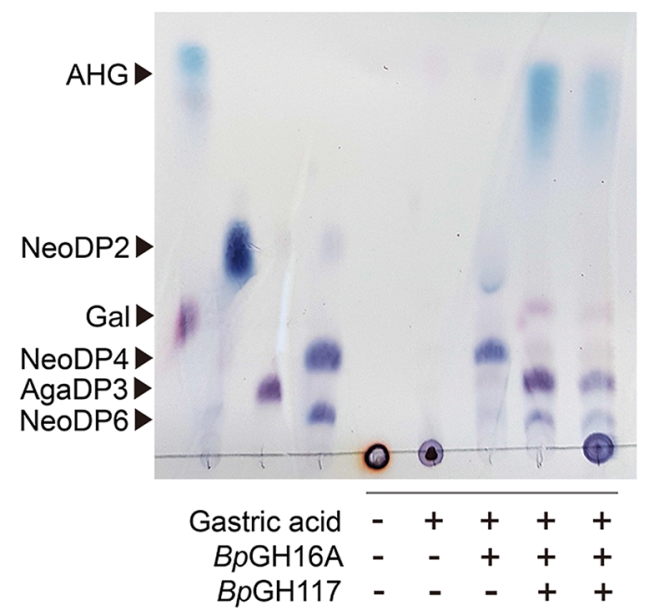

C

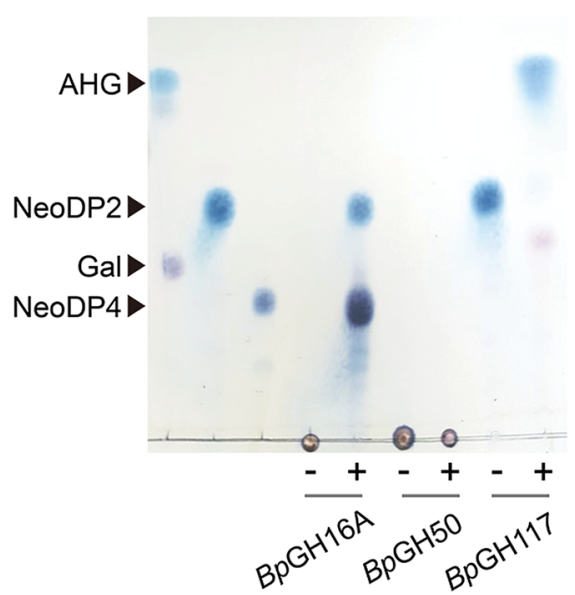

D

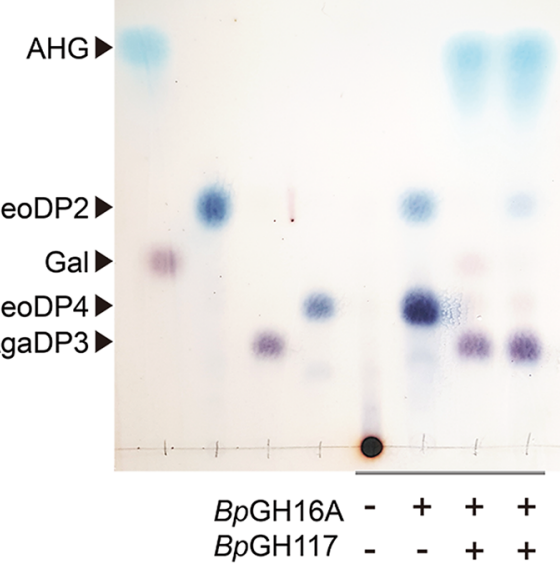

$\mathbf{F}$

$B p \mathrm{GH} 16 \mathrm{~A}$

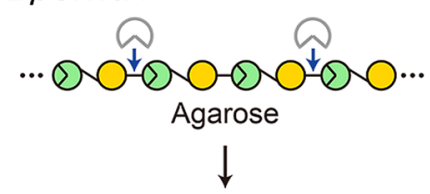

BpGH117

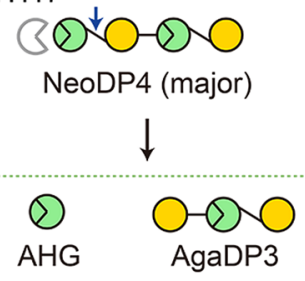


4Figure 2. $B p$ GH16A and BpGH117 are the key enzymes for the accumulation of AgaDP3 from agarose in $B$. plebeius. (A) The PUL of $B$. plebeius. Numbers below gene arrows are locus tag numbers without their prefix, BACPLE. Based on the sequence analysis, three genes located in the PUL of B. plebeius-i.e., BACPLE_01670, BACPLE_01671, and BACPLE_01683-encoding BpGH16A, BpGH117, and BpGH50, respectively, are related to the agarolytic mechanism. Abbreviations: MFS, Major facilitator superfamily; HTCS, hybrid two-component system. (B) Purification of the agarose degradation pathway enzymes, BpGH16A, BpGH50, and BpGH117, originating from $B$. plebeius. (C) Enzymatic activities of purified recombinant $B p \mathrm{GH} 16 \mathrm{~A}, B p \mathrm{GH} 50$, and $B p \mathrm{GH} 117$. The agarase activities of $B p \mathrm{GH} 16 \mathrm{~A}$ and $B p \mathrm{GH} 50$ were verified by the enzymatic reactions of each enzyme with agarose as the substrate. The NABH activity of $B p G H 117$ was verified by the enzymatic reaction with NeoDP2 as the substrate. The reaction products were analyzed by TLC. (D) Simulation of the agarolytic mechanism of $B$. plebeius using the sequential and the simultaneous enzymatic reactions of BpGH16A and $B p$ GH117 with agarose. Lanes 1-4, the standards of the agar-derived sugars; lane 5, the agarose substrate; lane 6 , the reaction products of $B p \mathrm{GH} 16 \mathrm{~A}$ using agarose; lane 7, the reaction products of $B p \mathrm{GH} 117$ with the reaction products of $B p \mathrm{GH} 16 \mathrm{~A}$; lane 8 , simultaneous enzymatic reactions of $B p \mathrm{GH} 16 \mathrm{~A}$ and $B p \mathrm{GH} 117$ using agarose. (E) Effects of treatment of agarose with simulated gastric fluid on sequential or simultaneous hydrolysis of agarose using $B p$ GH16A and BpGH117. The reaction products obtained from each step of agarose hydrolysis were analyzed by TLC. Lanes 1-3, the standards of agar-derived sugars, AHG, D-galactose (Gal), NeoDP2, AgaDP3, NeoDP4, and NeoDP6; lane 4, agarose substrate; lane 5, treatment of agarose using a simulated gastric fluid; lane 6 , reaction products of $B p \mathrm{GH} 16 \mathrm{~A}$ with agarose treated using a simulated gastric fluid; lane 7 , reaction products of $B p \mathrm{GH} 117$ with the reaction products of $B p \mathrm{GH} 16 \mathrm{~A}$; lane 8, reaction products obtained from the simultaneous reaction of $B p \mathrm{GH} 16 \mathrm{~A}$ and $B p \mathrm{GH} 117$ with agarose treated using a simulated gastric fluid. (F) Proposed mechanism of agarose degradation by $B p \mathrm{GH} 16 \mathrm{~A}$ and $B p \mathrm{GH} 117$ based on the results of in vitro enzymatic reactions.

The enzymatic reactions catalyzed both sequentially and simultaneously by BpGH16A and Bp GH117 showed that agarose is degraded into AgaDP3 and AHG (Fig. 2D). These results are in good agreement with those obtained from the fermentation (Fig. 1B) and in vitro reactions using the crude enzymes of $B$. plebeius on agarose (Fig. 1C,D). We also investigated the effect of a simulated gastric fluid on the agarose degradation pathway of $B$. plebeius. Although the treatment of agarose with a simulated gastric fluid might have partially cleaved the glycosidic linkages of agarose, as in the mild acid hydrolysis of agarose ${ }^{34}$, we obtained the same results with regard to the agarose degradation pathway and reaction products of $B p \mathrm{GH} 16 \mathrm{~A}$ and $B p \mathrm{GH} 117$ under the simulated gastric fluid conditions (Fig. 2E) as under in vitro enzymatic reaction conditions (Fig. 2D). Therefore, we suggest that in the agarose degradation pathway, B. plebeius accumulates AgaDP3 and AHG (Fig. 2F).

Meanwhile, although we did not verify which SusCD complex in B. plebeius is responsible for importing NeoDP4 into the periplasmic space, one of the two SusCD complexes, BACPLE 01697-01698 and BACPLE 01704-01705, found in the PUL of B. plebeius (Fig. 2A) might function as a transporter of NeoDP4 into the periplasmic space.

AgaDP3 utilization by probiotic strain B. infantis. Because AgaDP3 was accumulated during the utilization of agarose by B. plebeius, as described above, we speculated on the metabolic fate of the accumulated AgaDP3 in the human gut. Agarooligosaccharides (AOSs; agarooligosaccharides with galactose on the nonreducing end) and NAOSs have prebiotic potential because they modulate the composition of the gut microbiota, thereby preventing gut dysbiosis ${ }^{35}$ and stimulating the growth of beneficial gut bacteria such as lactobacilli and bifidobacteria ${ }^{36}$.

AgaDP3 was suggested as a prebiotic oligosaccharide in a previous study because of five distinct Bifidobacterium strains tested, Bifidobacterium adolescentis 1.2190 and Bifidobacterium infantis 1.2202 utilized AgaDP $3^{37}$. However, the AgaDP3 utilization pathway adopted by these Bifidobacterium strains, and the key enzymes associated with AgaDP3 utilization have not been fully elucidated. As in a previous study ${ }^{37}$, AgaDP3 was also utilized by a well-known probiotic strain, $B$. infantis (Fig. 3A,B). Based on the observation of crude in vitro enzyme reactions, the AgaDP3 degradation pathway adopted by $B$. infantis is as follows. AgaDP3 is hydrolyzed into galactose and NeoDP2, probably by the action of the intracellular agarolytic $\beta$-galactosidases of $B$. infantis (Fig. 3C). Then, the galactose intracellularly produced from AgaDP3 is used by B. infantis as an energy source (Fig. 3A,B), whereas the produced NeoDP2 is not further degraded by B. infantis (Fig. 3D). The fermentation profiles revealed that most of AgaDP3 supplied as a carbon source was used for producing acetate than for the cell growth of B. infantis (Fig. 3B).

AgaDP3-degrading $\beta$-galactosidases in $B$. infantis. The results obtained from the fermentation profiles of $B$. infantis under AgaDP3 condition (Fig. 3A) and in vitro crude enzyme reactions with AgaDP3 (Fig. 3C) demonstrated that $B$. infantis degrades AgaDP3 into NeoDP2 and D-galactose via its agarolytic $\beta$-galactosidase activity. $B$. infantis has five genes encoding $\beta$-galactosidase, however one of them (i.e., Blon_0268) was excluded because, according to the previous studies, Blon_0268 preferred $\beta$-1,6-linkages in $\beta$-1,6-D-galactobiose ${ }^{38}$. Therefore, we tested four genes encoding $\beta$-galactosidase, Blon_2016, Blon_2123, Blon_2334, and Blon_2416 corresponding to Bga42A, Bga42B, Bga2A, and Bga42C, respectively, to identify the enzymes responsible for the agarolytic $\beta$-galactosidase activity with regard to AgaDP3 in B. infantis (Fig. 3C).

Four recombinant $\beta$-galactosidases originating from B. infantis-namely, Bga42A, Bga42B, Bga2A, and Bga42C-were prepared to test whether they could hydrolyze AgaDP3 (Fig. 3E). The functional expression of these $\beta$-galactosidases was verified by determining the $\beta$-galactosidase activities of the enzymes with regard 
A

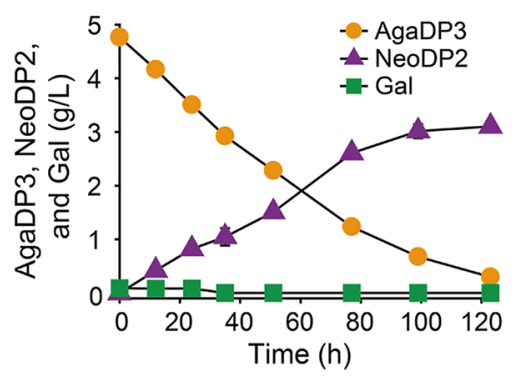

C

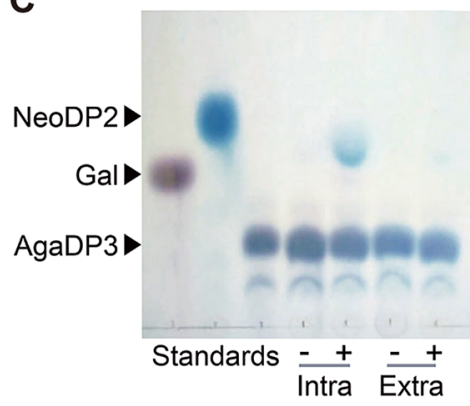

B

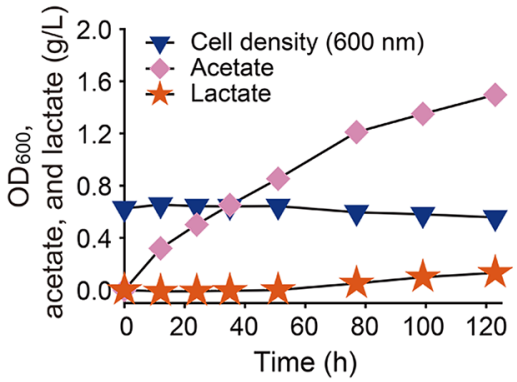

D

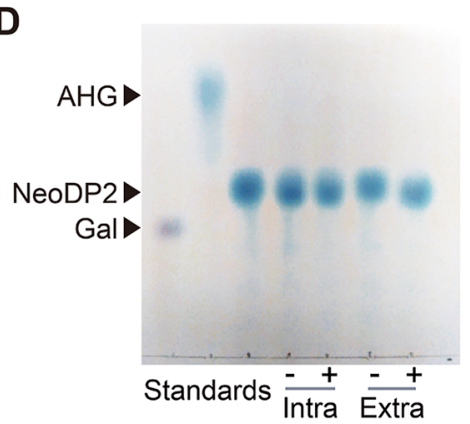

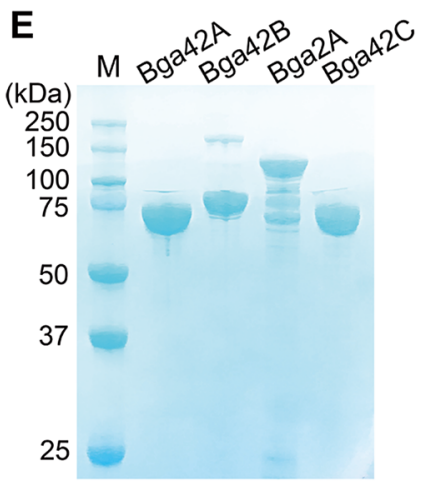
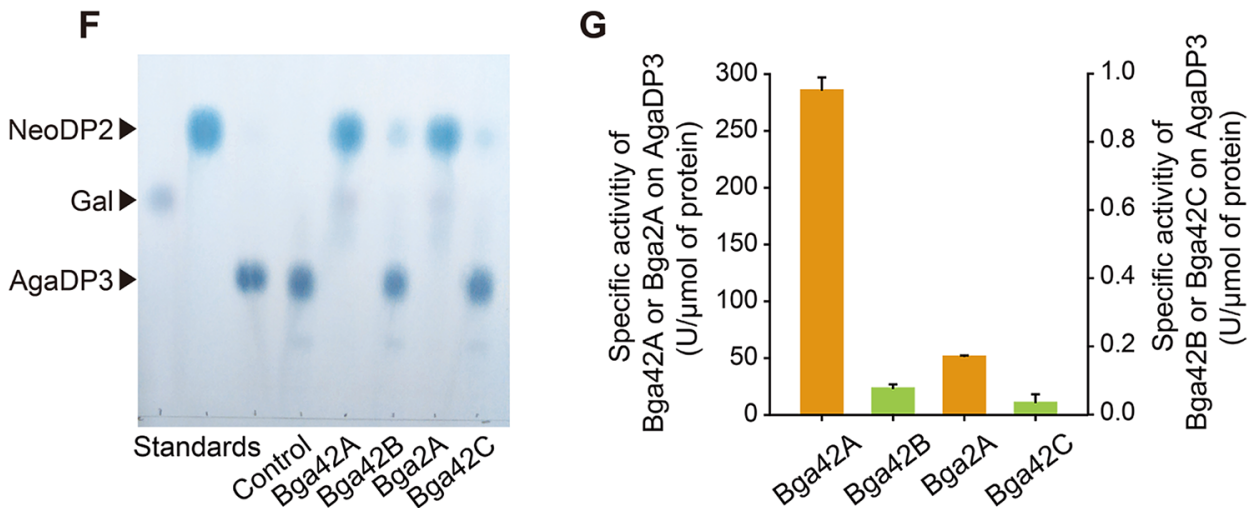

Figure 3. B. infantis extracts energy from AgaDP3 via its agarolytic $\beta$-galactosidase activity, and B. plebeius ultimately acts on NeoDP2, resulting in the production of AHG. (A and $\mathbf{B}$ ) Time courses of AgaDP3 fermentation by $B$. infantis. Error bars mean \pm S.D. (C) In vitro agarolytic $\beta$-galactosidase activities of extracellular crude enzymes (Extra) and cell-free lysate (Intra) obtained from B. infantis on AgaDP3. (D) In vitro NABH activities of extracellular crude enzymes (Extra) and cell-free lysate (Intra) obtained from $B$. infantis on AgaDP3. (E) SDS-PAGE analysis of the overexpressed and purified recombinant $\beta$-galactosidases Bga42A, Bga42B, Bga $2 \mathrm{~A}$, and Bga42C originating from B. infantis. (F) TLC analysis of the reaction products of recombinant $\beta$-galactosidases from B. infantis-i.e., Bga42A, Bga42B, Bga2A, and Bga42C-with AgaDP3. (G) Comparison of the specific agarolytic $\beta$-galactosidase activities of the four $\beta$-galactosidases on AgaDP3. Error bars represent means \pm S.D.

to lactose (Supplementary Fig. 4). Interestingly, of the four recombinant $\beta$-galactosidases, Bga42A and Bga2A exhibited agarolytic $\beta$-galactosidase activity with regard to AgaDP3 (Fig. 3F,G). Although the two other enzymes, Bga42B and Bga42C, also showed agarolytic $\beta$-galactosidase activity, those specific activities were marginal as compared to those obtained from Bga42A and Bga2A (Fig. 3G).

To date, agarolytic $\beta$-galactosidase activity with regard to galactose residues at the non-reducing ends of AOSs including AgaDP3 has only been observed in a marine bacterium, Vibrio sp. EJY3, and a gut bacterium, $B$. uniformis NP1 ${ }^{11,39}$. The $\beta$-galactosidases originating from $B$. infantis have been biochemically well-characterized using various substrates such as human milk oligosaccharides (HMOs) in the previous studies ${ }^{38,40}$; however, they have not been tested yet with respect to the degradation of agar-derived sugars such as AgaDP3. In the present study, we observed agarolytic $\beta$-galactosidase activities of Bga42A and Bga2A originating from B. infantis, a probiotic gut bacterium. Intriguingly, Bga42A is the first enzyme belonging to GH42 that exhibits an agarolytic $\beta$-galactosidase activity.

In the PUL of B. plebeius, the three genes, BACPLE_01672, BACPLE_01673, and BACPLE_01706, belong to GH2. Therefore, the agarolytic $\beta$-galactosidase activities of those purified recombinant proteins on AgaDP3 were 

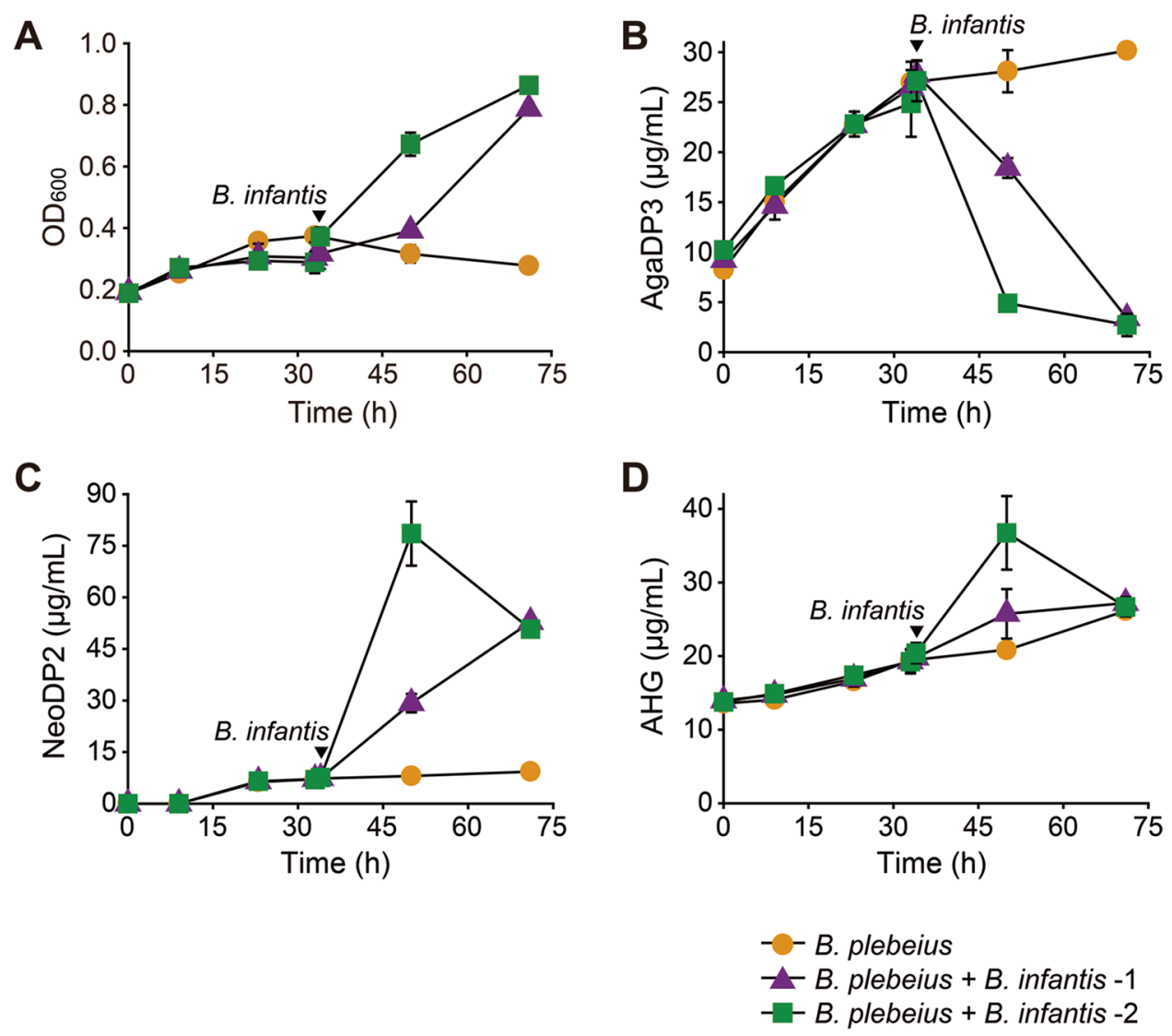

Figure 4. Sequential co-culture of B. plebeius (inoculated initially) and B. infantis (inoculated later at the two different levels of CFUs) for simulating the cooperative actions of the two distinct gut bacteria with regard to agarose degradation. (A) Profiles of cell growth represented by cell density measured at $600 \mathrm{~nm}$ and fermentation products, AgaDP3 (B), NeoDP2 (C), and AHG (D), during the fermentation of pretreated agarose with $B$. plebeius only (B. plebeius in A-D), B. plebeius and B. infantis with a low level of inoculum $(B$. plebeius $+B$. infantis -1 in A-D), or B. plebeius and B. infantis with a high level of inoculum (B. plebeius $+B$. infantis -2 in $A-D)$. Error bars represent means \pm S.D.

measured in this study. The results revealed that among the three enzymes belonging to GH2, the recombinant protein of BACPLE_01672 showed the agarolytic $\beta$-galactosidase activity on AgaDP3 (Supplementary Fig. 5). However, the specific activity of the recombinant protein of BACPLE_01672 was significantly lower than that of Bga42A and Bga2A originating from B. infantis (Supplementary Fig. 5). In addition, during the fermentation of B. plebeius under the AgaDP3 condition, the concentration of AgaDP3 in the culture medium did not decreased (Supplementary Fig. 6A). The results of in vitro crude enzyme reactions showed that the crude enzymes of $B$. plebeius did not exhibit the agarolytic $\beta$-galactosidase activity on AgaDP3 (Supplementary Fig. 6B).

Sequential co-culture of $B$. plebeius and $B$. infantis with pretreated agarose. During the fermentation of NeoDP2 by B. plebeius, AHG was accumulated in the culture supernatant (Supplementary Fig. 7). Therefore, we hypothesized that agarose might be completely hydrolyzed into its monomers, galactose and AHG, through the cooperative actions of the two distinct gut bacteria, B. plebeius and $B$. infantis. To prove this, we sequentially co-cultured $B$. plebeius and $B$. infantis with pretreated agarose (Fig. 4A-D). When B. plebeius growth reached the stationary phase at $34 \mathrm{~h}$, cells of $B$. infantis were inoculated into the culture broth with an optical density at $600 \mathrm{~nm}\left(\mathrm{OD}_{600}\right)$ of 0.013 or 0.083 (corresponding to $\sim 1.5 \times 10^{6}$ or $\sim 9.2 \times 10^{6}$ colony-forming units $(\mathrm{CFU}) / \mathrm{mL}$, respectively) ${ }^{41}$. Agarose degradation intermediates (AgaDP3, NeoDP2, and AHG) were produced during the fermentation of pretreated agarose by B. plebeius and B. infantis (Supplementary Fig. 8). As already shown in Fig. 1B, during the fermentation of pretreated agarose with B. plebeius, AgaDP3 was accumulated in the culture broth (Fig. 4B). Interestingly, after the inoculation with $B$. infantis at $34 \mathrm{~h}$, the concentration of AgaDP3 decreased significantly, and NeoDP2 was produced by the agarolytic $\beta$-galactosidase activity of B. infantis on AgaDP3 (Fig. 4B,C). The AHG concentration in the culture supernatant was also increased by the cooperative degrading actions of the two distinct bacteria on the pretreated agarose (Fig. 4D). The highest concentration of AHG produced from the sequential co-culture of B. plebeius and B. infantis was $36.8 \mathrm{mg} / \mathrm{L}$ (Fig. 4D). However, after $50 \mathrm{~h}$, a decrease of AHG concentration in the culture of B. plebeius $+B$. infantis- 2 was observed (Fig. 4D); that is probably due to the conversion of AHG by promiscuous activities of enzymes from $B$. plebeius or B. infantis ${ }^{42}$. Also, to determine whether the presence of agarose support cell growth of the co-culture 


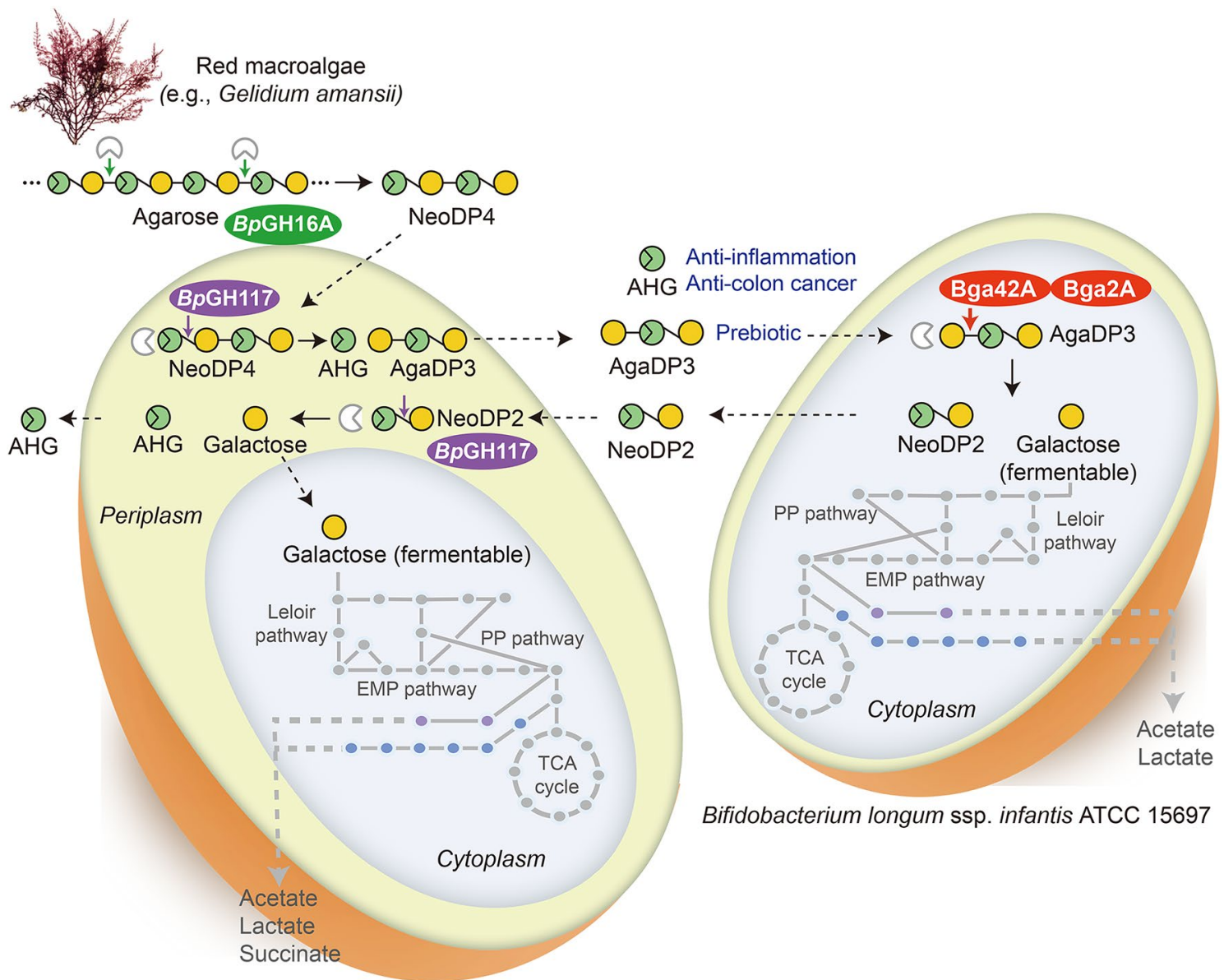

Bacteroides plebeius DSM 17135

Figure 5. Cooperative actions of two distinct gut bacteria, B. plebeius and B. infantis, enable the complete degradation of seaweed agar. Agarose is initially decomposed into NeoDP4 by BpGH16A, and NeoDP4 is then further hydrolyzed into AgaDP3 and AHG by BpGH117. B. infantis hydrolyzes AgaDP3 into NeoDP2 and galactose using Bga42A or Bga2A. Finally, NeoDP2 is hydrolyzed into the monomeric sugars, galactose and AHG by $B p \mathrm{GH} 117$.

of both bacteria, the growth profiles of the sequential co-culture of B. plebeius and then B. infantis grown in the presence of agarose or in the absence of agarose were compared but they were almost identical (Supplementary Fig. 9). These results imply that although the agarose-based sugars, AgaDP3, NeoDP2, and AHG, were released by the actions of $B$. plebeius and $B$. infantis, the amounts of those sugars were not sufficient to support their cell growth.

\section{Discussion}

In this study, we propose a cooperative relationship between two distinct human gut symbionts that results in complementary metabolic activities on agarose, which may explain consuming red seaweed is associated with therapeutic or preventative effects against various diseases and health concerns. First, we characterized the agarose degradation pathway of B. plebeius, a microbiome species predominantly observed in East Asians ${ }^{3,11}$. We found that the incomplete agarose degradation by B. plebeius leads to the accumulation of oligosaccharides, primarily AgaDP3 (Figs. 1 and 2). Interestingly, the missing link in the agarose degradation pathway of B. plebeius is complemented by the actions of agarolytic $\beta$-galactosidases of a well-known probiotic strain, $B$. infantis (Fig. 3). Recently, it was demonstrated that in addition to B. infantis ATCC 15697, other probiotic Bifidobacterium strains assimilating HMOs also have an agarolytic $\beta$-galactosidase activity ${ }^{43}$. Second, this unique microbial symbiosis between two distinct gut bacteria, $B$. plebeius and B. infantis, enables the production of AHG, a rare sugar possessing various physiological activities ${ }^{23,43}$, through the degradation of seaweed agarose (Fig. 5).

This is the first proposed degradation pathway showing how agarose or AOSs from red seaweeds agar are completely degraded into their monomers (i.e., AHG and galactose) by the unique cooperative actions of two distinct gut bacteria (Fig. 5). In the proposed pathway, first, BpGH16A, probably located at the cell surface, initially decomposes agarose polysaccharide into NeoDP4, and NeoDP4 is then imported into the periplasmic space (Fig. 5). Second, BpGH117, probably located at the periplasm, further degrades NeoDP4 into AHG and AgaDP3 (Fig. 5). AgaDP3 secreted from B. plebeius cells is utilized by $B$. infantis via its agarolytic activities of Bga42A and Bga2A to degrade AgaDP3 into galactose and NeoDP2 (Fig. 5). Finally, NeoDP2 secreted from $B$. 
infantis cells decomposed to AHG and galactose by the action of BpGH117 of B. infantis (Fig. 5). In this study, we did not verify which SusCD complex in B. plebeius plays a role in importing agar-induced sugars, NeoDP4 and NeoDP2. Considering the general PUL mechanism, BACPLE 01697-01698 and BACPLE 01704-01705, which encode SusCD proteins in the PUL of B. plebeius (Fig. 2A), are expected to be responsible for importing agar-induced sugars.

B. infantis ATCC 15697 is isolated from the intestine of infant (https://www.atcc.org/products/15697) where HMOs are abundant, and it is known as a typical member of the gastrointestinal microbiota of breastfed infants ${ }^{44}$. Furthermore, for the cultivation of $B$. infantis ATCC 15697, HMOs such as lacto- $N$-tetraose, lacto- $N$-neotetraose, and 2'-fucosyllactose, are the preferred carbon sources than AgaDP3 in terms of cell growth rate and maximum cell density measured at $\mathrm{OD}_{600}{ }^{43,45}$; this implies that Bga42A and Bga2A participate in the degradation of $\mathrm{HMOs}^{40}$ and AgaDP3, but they favorably degrade HMOs than AgaDP3.

The molecular mechanisms of cooperative degradation of red seaweed agarose by two human gut bacteria, B. plebeius and B. infantis, demonstrated in this study is one of a few simple but unique examples elucidating the complex interactions in numerous gut microbiota and their effects on host physiology. The cooperative action of the human gut bacteria on red seaweed agarose implies that other polysaccharides that are more complex than agarose may be also degraded by cooperative actions of human gut bacteria in the real conditions of the human gut.

For the verification of this system in vivo using an animal model, porphyran should be considered for supporting the colonization of $B$. plebeius in the gut of animal models; this is because porphyran is a selective nutrient for $B$. plebeius in the competitive gut environment ${ }^{46,47}$. Although agarose is not used as a dietary polysaccharide, agarose is the major component of agar that is widely used for making various types of foods such as jelly and noodles. Therefore, for the future in vivo study using an animal model, food-grade edible agar should be considered along with native porphyran.

\section{Methods}

Bacterial growth. We cultured B. plebeius DSM 17135 (DSMZ, Braunschweig, Germany) in Columbia broth containing $5 \%(\mathrm{v} / \mathrm{v})$ sheep blood or the minimal broth as previously described ${ }^{29}$ with a slight modification as follows: $4.5 \mathrm{~mL}$ of chopped meat carbohydrate broth (Thermo Fisher Scientific, Waltham, MA, USA) or chopped meat glucose broth (Thermo Fisher Scientific), $0.5 \mathrm{~mL}$ of trace mineral solution, $0.5 \mathrm{~mL}$ of purine and pyrimidine solution, $0.5 \mathrm{~mL}$ of vitamin mixture, $0.5 \mathrm{~mL}$ of amino acid solution, $0.2 \mathrm{~mL}$ of additional nutrient solution, and $0.6 \mathrm{~mL}$ of a carbon source such as agarose, AgaDP3, NeoDP2, or glucose, with a final concentration of $5 \mathrm{~g} / \mathrm{L}$ each.

We cultured B. infantis ATCC 15697 in de Man, Rogosa and Sharpe (MRS; Sigma-Aldrich, St. Louis, MO, USA) or synthetic MRS (sMRS) broth ${ }^{48}$. The sMRS broth was composed of $10 \mathrm{~g} / \mathrm{L}$ peptone, $5 \mathrm{~g} / \mathrm{L}$ yeast extract, $2 \mathrm{~g} / \mathrm{L}$ anhydrous dipotassium phosphate, $5 \mathrm{~g} / \mathrm{L}$ anhydrous sodium acetate, $2 \mathrm{~g} / \mathrm{L}$ tribasic ammonium citrate, $0.2 \mathrm{~g} / \mathrm{L}$ magnesium sulfate heptahydrate, $0.05 \mathrm{~g} / \mathrm{L}$ manganese (II) sulfate, $1 \mathrm{~mL} / \mathrm{L}$ polysorbate $80,0.5 \mathrm{~g} / \mathrm{L}$ cysteine, and $5 \mathrm{~g} / \mathrm{L}$ carbon source such as AgaDP3.

The B. plebeius and B. infantis were cultured in a chamber with an anaerobic atmosphere comprising $90 \% \mathrm{~N}_{2}$ and $10 \% \mathrm{CO}_{2}$, or $90 \% \mathrm{~N}_{2}, 5 \% \mathrm{H}_{2}$, and $5 \% \mathrm{CO}_{2}$ (Airgas, Radnor, PA, USA) at $37^{\circ} \mathrm{C}$. During the fermentation, cell growth was monitored by measuring the optical density at $600 \mathrm{~nm}$.

Preparation of crude enzymes. To prepare crude enzymes, $5 \mathrm{~mL}$ of each cell culture of B. plebeius or $B$. infantis grown on culture media supplemented with agarose or AgaDP3, respectively, was centrifuged at $2,880 \times g$ and $4{ }^{\circ} \mathrm{C}$ for $30 \mathrm{~min}$. The cell pellet and supernatant were then separated to obtain a cell-free crude extract and extracellular crude enzymes, respectively ${ }^{49}$.

The cell pellet was washed with $5 \mathrm{~mL}$ of phosphate-buffered saline (PBS; $\mathrm{pH}$ 7.4) to obtain the cell-free crude extract. The washed cell pellet obtained by centrifugation at $2,880 \times g$ and $4{ }^{\circ} \mathrm{C}$ for $30 \mathrm{~min}$ was resuspended with $5 \mathrm{~mL}$ of $20 \mathrm{mM}$ Tris-HCl buffer ( $\mathrm{pH} 7.0$ ), and the cells were disrupted by sonication for $3 \mathrm{~min}$. The supernatant containing cell-free crude extract was collected by centrifugation at $24,041 \times g$ and $4{ }^{\circ} \mathrm{C}$ for $30 \mathrm{~min}$. The soluble cell-free crude extract was concentrated using an Amicon ultrafiltration membrane (Millipore, Billerica, MA, USA).

To obtain the extracellular crude enzymes, the culture supernatant was directly concentrated using an Amicon ultrafiltration membrane with a membrane nominal molecular weight limit of $10 \mathrm{kDa}$ (Millipore). The media components in the concentrated crude extracellular enzymes were washed by adding $10 \mathrm{~mL}$ of $20 \mathrm{mM}$ Tris- $\mathrm{HCl}$ buffer ( $\mathrm{pH} 7.0$ ) followed by centrifugation at $2,880 \times g$ and $4{ }^{\circ} \mathrm{C}$ for $30 \mathrm{~min}$. This washing step was repeated three times. The protein concentrations of the cell-free crude extract and extracellular crude enzymes were determined using a bicinchoninic acid (BCA) protein assay kit (Thermo Fisher Scientific).

Cloning, overexpression, and purification of recombinant proteins. The genomic DNAs of B. plebeius and $B$. infantis were extracted using a commercial DNA isolation kit (Qiagen, Germantown, MD, USA) for cloning. Three genes from B. plebeius-namely BACPLE_01670 (bpGH16A), BACPLE_01671 (bpGH117), and BACPLE_01683 (bpGH50)_-and four genes from B. infantis-namely Blon_2016 (bga42A), Blon_2123 (bga42B), Blon_2334 (bga2A), and Blon_2416 (bga42C)—were amplified from each genomic DNA by polymerase chain reaction (PCR) using the primers described in Table 1 . The predicted signal sequences at the $N$-termini of BACPLE_01670, BACPLE_01671, and BACPLE_01671 were removed to facilitate protein expression. Sequentially, the PCR products of each gene and pET21a (Novagen, Madison, WI, USA) were digested with restriction enzymes and ligated using a T4 DNA ligase (Biolabs, Ipswich, MA, USA). The resulting pET21a vec- 


\begin{tabular}{|c|c|}
\hline Primer & Sequence (restriction sites are underlined) \\
\hline F_Bpgh16A (NdeI) & ATACATATGGCAGAA AATTTA AATAATAAATCATACGAGTG \\
\hline R_Bpgh16A (NotI) & AGTGCGGCCGCTTCTTCTGGGACCAGTGATTAAACCC \\
\hline F_Bpgh50 (NdeI) & ATACATATGAATACAGGCAATACACAGACTATTGCCG \\
\hline R_Bpgh50 (NotI) & AGTGCGGCCGCTTTACGTTCTTTTGATTCACCCTTAGCAG \\
\hline F_ Bpgh117 (NdeI) & ATACATATGTTGAGTGTTCCGTTCTTCGCTTTGTCATGTG \\
\hline R_Bpgh117 (NotI) & AGTGCGGCCGCTTTGTCGAAATAATCTATAAGATTATAAAC \\
\hline F_ BACPLE_01672 (NdeI) & ATACATATGTCTGATTCAAATGTTGATTTCAATAAAGA \\
\hline R_BACPLE_01672 (XhoI) & AGTCTCGAGTTTTATATTAATTGTTAGTTTATTCGACTG \\
\hline F_ BACPLE_01673 (NdeI) & ATACATATGGGAACCTCCACTAAAGTGGATT \\
\hline R_BACPLE_01673 (XhoI) & AGTCTCGAGATGTGATATAGGGTGGGAAATCA \\
\hline F_ BACPLE_01706 (NdeI) & ATACATATGATGAACTTGAACTTAAAATCTATTTTTTCAT \\
\hline R_BACPLE_01706 (XhoI) & AGTCTCGAGATATATTTTTCTGCCCATTTCCTTAAG \\
\hline F_bga2A (NdeI) & GGAATTCATATGACAGACGTCACACATGTCGATCGC \\
\hline R_bga2A (HindIII) & GAAGCTTGATCAGCTCGAGATCGACGTCGAGG \\
\hline F_bga42A (NdeI) & GGAATTCATATGGAACATAGAGCGTTCAAGTGGCCGCA \\
\hline R_bga42A (NotI) & GGCGGCCGCCAGCTTGACGACGAGTACGCCGTTG \\
\hline F_bga42B (BamHI) & GGAATTGGATCCATGCGTGCGCGACGTGACTTCGCATG \\
\hline R_bga42B (NotI) & GGCGGCCGCCACCGACGGGTTCGGGCGTTTCAT \\
\hline F_bga42C (NdeI) & GGAATTCATATGACCGACACCATGGCACACACCCAAC \\
\hline R_bga42C (HindIII) & GAAGCTTTGCCGCGGTGCGCACCACCG \\
\hline
\end{tabular}

Table 1. Primers used in this study.

\begin{tabular}{|c|c|c|}
\hline Strain or plasmid & Relevant characteristic, genotype, or gene sequence & Source \\
\hline \multicolumn{3}{|l|}{ Strain } \\
\hline Bacteroides plebeius DSM 17135 & Isolated from feces of Japanese individuals & $\begin{array}{l}\text { DSMZ } \\
\text { (Braunschweig, Germany) }\end{array}$ \\
\hline Bifidobacterium longum ssp. infantis ATCC 15697 & Isolated from feces of human infant & $\begin{array}{l}\text { ATCC } \\
\text { (Manassas, VA, USA) }\end{array}$ \\
\hline Escherichia coli $\mathrm{DH} 5 a$ & $\begin{array}{l}\text { F- } \text { 90lacZ } \Delta \text { M15 } \Delta \text { (lacZYA-argF) U169 recA1 endA1 hsdR17 (rK- mK+) phoA supE44 } \lambda \text { - thi-1 } \\
\text { gyrA96 relA1 }\end{array}$ & $\begin{array}{l}\text { Invitrogen } \\
\text { (Carlsbad, CA, USA) }\end{array}$ \\
\hline Escherichia coli BL21(DE3) & $\mathrm{F}-\operatorname{omp} \mathrm{T} h s d S_{B}\left(\mathrm{r}_{\mathrm{B}^{-}}, \mathrm{m}_{\mathrm{B}^{-}}\right)$gal dcm (DE3) & $\begin{array}{l}\text { Invitrogen } \\
\text { (Carlsbad, CA, USA) }\end{array}$ \\
\hline \multicolumn{3}{|l|}{ Plasmid } \\
\hline pET21a & T7 promoter with MCS, pBR322 replicon, $A_{m p}{ }^{R}$ & $\begin{array}{l}\text { Novagen } \\
\text { (Burlington, MA, USA) }\end{array}$ \\
\hline $\mathrm{p} B \operatorname{pgh} 16 A$ & pET21a harboring Bpgh16A & This study \\
\hline $\mathrm{pBpgh50}$ & pET21a harboring Bpgh50 & This study \\
\hline $\mathrm{p}$ Bpgh117 & pET21a harboring Bpgh117 & This study \\
\hline pBACPLE_01672 & pET21a harboring BACPLE_01672 & This study \\
\hline pBACPLE_01673 & pET21a harboring BACPLE_01673 & This study \\
\hline pBACPLE_01706 & pET21a harboring BACPLE_01706 & This study \\
\hline $\mathrm{p} b g a 2 A$ & pET21a harboring bga2A & This study \\
\hline $\mathrm{p} b g a 42 A$ & pET21a harboring $b g a 42 A$ & This study \\
\hline $\mathrm{p} b g a 42 B$ & pET21a harboring $b g a 42 B$ & This study \\
\hline pbga42C & pET21a harboring bga42C & This study \\
\hline
\end{tabular}

Table 2. Strains and plasmids used in this study.

tor harboring each target gene was then transformed into Escherichia coli BL21(DE3) (Novagen, Seoul, Republic of Korea). Strains and plasmids used in this study are listed in Table 2.

To overexpress the recombinant proteins, E. coli BL21(DE3) harboring each gene was grown at $37^{\circ} \mathrm{C}$ in Luria-Bertani broth (Merck, Darmstadt, Germany) containing $100 \mu \mathrm{g} / \mathrm{mL}$ of ampicillin until the mid-exponential phase of growth. Protein expression was then induced by adding $0.1 \mathrm{mM}$ isopropyl- $\beta$ - $\mathrm{D}$-thiogalactopyranoside (IPTG; Sigma-Aldrich) at $16^{\circ} \mathrm{C}$ and further incubating for $16 \mathrm{~h}$. The cells were harvested by centrifugation at $12,857 \times g$ for $40 \mathrm{~min}$ at $4^{\circ} \mathrm{C}$, and the cell pellet was resuspended in a $20 \mathrm{mM}$ Tris- $\mathrm{HCl}$ buffer $(\mathrm{pH} 7.4)$ for the purification process. 
To purify each of the recombinant proteins, the resuspended cells were disrupted using a sonicator (Branson, Gunpo, Korea), and the supernatant was collected by centrifugation at $24,041 \times g$ for $1 \mathrm{~h}$ at $4{ }^{\circ} \mathrm{C}$. Each of the recombinant enzymes was purified using a His-Trap column (GE Healthcare, Buckinghamshire, UK). After purification, the recombinant proteins were identified by sodium dodecyl sulfate-polyacrylamide gel electrophoresis (SDS-PAGE) analysis, and protein concentrations were measured using a BCA protein assay kit (Thermo Fisher Scientific).

In vitro agarase activity. We incubated $100 \mu \mathrm{L}$ of a reaction mixture comprising $1.5 \mathrm{mg} / \mathrm{mL}$ crude enzymes (i.e., cell-free extract or extracellular enzymes) and $0.25 \%(\mathrm{w} / \mathrm{v})$ agarose in $20 \mathrm{mM}$ Tris-HCl buffer (pH 7.0) at $30{ }^{\circ} \mathrm{C}$ and $200 \mathrm{rpm}$ for $12 \mathrm{~h}$ to measure the agarase activity of the crude enzymes of $B$. plebeius. The enzymatic reactions were stopped by heating the reaction samples at $95^{\circ} \mathrm{C}$ for $2 \mathrm{~min}$.

To measure the agarase activities of $B p \mathrm{GH} 16 \mathrm{~A}$ and $B p \mathrm{GH} 50,4 \mathrm{~mL}$ of a reaction mixture comprising $0.08 \mathrm{mg} /$ $\mathrm{mL}$ (equivalent to $2.32 \mu \mathrm{M}$ ) $B p \mathrm{GH} 16 \mathrm{~A}$ or $0.06 \mathrm{mg} / \mathrm{mL}$ (equivalent to $1.01 \mu \mathrm{M}$ ) $B p \mathrm{GH} 50$ and $1 \%$ (w/v) agarose or $5 \mathrm{~g} / \mathrm{L}$ NeoDP4 in $20 \mathrm{mM}$ Tris- $\mathrm{HCl}$ buffer ( $\mathrm{pH} 7.0$ ) was incubated at $40^{\circ} \mathrm{C}$ and $200 \mathrm{rpm}$ for $6 \mathrm{~h}$. The enzymatic reactions were stopped by heating the reaction samples in boiling water for $3 \mathrm{~min}$. After terminating the enzymatic reactions, the reaction products from each sample were identified by LC/MS - IT - TOF, TLC, or high-performance liquid chromatography (HPLC) analyses.

In vitro NABH activity. We incubated $100 \mu \mathrm{L}$ of a reaction mixture comprising $1.5 \mathrm{mg} / \mathrm{mL}$ crude enzymes (i.e., cell-free extract or extracellular enzymes) and $2.5 \mathrm{mg} / \mathrm{mL}$ NeoDP2 in $20 \mathrm{mM}$ Tris-HCl buffer (pH 7.0) at $30^{\circ} \mathrm{C}$ and $200 \mathrm{rpm}$ for $12 \mathrm{~h}$ to measure the NABH activity of the crude enzymes of $B$. plebeius. The enzyme reactions were stopped by heating the reaction samples at $95^{\circ} \mathrm{C}$ for $2 \mathrm{~min}$.

To measure the NABH activity of $B p \mathrm{GH} 117,4 \mathrm{~mL}$ of a reaction mixture comprising $0.02 \mathrm{mg} / \mathrm{mL}$ (equivalent to $0.46 \mu \mathrm{M}$ ) BpGH117 and $5 \mathrm{mg} / \mathrm{mL}$ NeoDP2 in $20 \mathrm{mM}$ Tris-HCl buffer (pH 7.0) was incubated at $40^{\circ} \mathrm{C}$ and $200 \mathrm{rpm}$ for $2 \mathrm{~h}$. The enzymatic reaction was stopped by heating the reaction sample in boiling water for $3 \mathrm{~min}$. After terminating the enzymatic reactions, the reaction products from each sample were identified by TLC and HPLC analyses.

Sequential or simultaneous enzymatic hydrolysis of agarose. For the sequential enzymatic reactions of $B p \mathrm{GH} 16 \mathrm{~A}$ and $B p \mathrm{GH} 117$, we first incubated a reaction mixture comprising $0.08 \mathrm{mg} / \mathrm{mL}$ (equivalent to

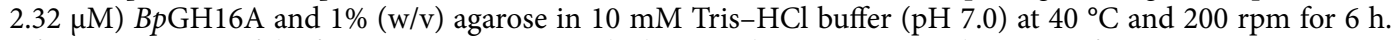
After inactivation of the first enzymatic reaction by heating the reaction sample at $95^{\circ} \mathrm{C}$ for $3 \mathrm{~min}, \mathrm{Bp} \mathrm{GH} 117$ was added to the reaction products of $B p \mathrm{GH} 16 \mathrm{~A}$ with a final concentration of $0.08 \mathrm{mg} / \mathrm{mL}$ (equivalent to $1.83 \mu \mathrm{M}$ ), and the reaction mixture was incubated at $40{ }^{\circ} \mathrm{C}$ and $200 \mathrm{rpm}$ for $2 \mathrm{~h}$. The final substrate loading was diluted twofold in the second reaction step.

For the simultaneous enzymatic reaction of $B p \mathrm{GH} 16 \mathrm{~A}$ and $B p \mathrm{GH} 117$, we incubated a reaction mixture comprising $B p \mathrm{GH} 16 \mathrm{~A}$ and $B p \mathrm{GH} 117$ with a final concentration of $0.08 \mathrm{mg} / \mathrm{mL}$ (equivalent to 2.32 and $1.83 \mu \mathrm{M}$ each, respectively) and $1 \%(\mathrm{w} / \mathrm{v})$ agarose in $10 \mathrm{mM}$ Tris- $\mathrm{HCl}$ buffer $(\mathrm{pH} 7.0)$ at $40{ }^{\circ} \mathrm{C}$ for $6 \mathrm{~h}$. The enzymatic reactions were then terminated by heating the reaction sample in boiling water for $3 \mathrm{~min}$. After the sequential or simultaneous enzymatic hydrolyses of agarose by $B p \mathrm{GH} 16 \mathrm{~A}$ and $B p \mathrm{GH} 117$, the reaction products were identified by TLC.

Effect of simulated gastric fluid on agarose hydrolysis. To investigate the effect of simulated gastric fluid on agarose hydrolysis, we incubated $1 \%(\mathrm{w} / \mathrm{v})$ agarose in a simulated gastric fluid comprising $0.2 \%(\mathrm{w} / \mathrm{v})$ sodium chloride in $0.7 \%(\mathrm{v} / \mathrm{v})$ hydrochloric acid $(\mathrm{pH} 1.11)$ at $37^{\circ} \mathrm{C}$ for $2 \mathrm{~h}$. The reaction sample was then neutralized to $\mathrm{pH} 7.0$, which is the $\mathrm{pH}$ of the distal colon, using $1 \mathrm{M} \mathrm{NaOH}$ solution, and pre-digested agarose was incubated with $B p \mathrm{GH} 16 \mathrm{~A}$ and $B p \mathrm{GH} 117$ either sequentially or simultaneously.

As described above, $B p$ GH16A with a final concentration of $0.08 \mathrm{mg} / \mathrm{mL}$ was incubated with $1 \%(\mathrm{w} / \mathrm{v})$ predigested agarose using a simulated gastric fluid as a substrate at $37^{\circ} \mathrm{C}$ for $2 \mathrm{~h}$. After terminating the first reaction by heating the reaction sample in boiling water for $3 \mathrm{~min}, B p \mathrm{GH} 117$ with a final concentration of $0.08 \mathrm{mg} / \mathrm{mL}$ was sequentially incubated with the first reaction products at $37^{\circ} \mathrm{C}$ for $2 \mathrm{~h}$. The second reaction was terminated by heating the reaction sample in boiling water for $3 \mathrm{~min}$. Bp GH16A and BpGH117 with final concentrations of $0.08 \mathrm{mg} / \mathrm{mL}$ each were incubated simultaneously with $1 \%(\mathrm{w} / \mathrm{v})$ pre-digested agarose using a simulated gastric fluid at $37^{\circ} \mathrm{C}$ for $2 \mathrm{~h}$.

Assay of agarolytic $\beta$-galactosidase activity. To determine the enzyme activities of the $\beta$-galactosidases from B. infantis ATCC 15697-i.e., Bga42A, Bga42B, Bga2A, and Bga42C-we incubated 1 nmol of each $\beta$-galactosidase in $100 \mu \mathrm{L}$ of $50 \mathrm{mM}$ sodium phosphate buffer ( $\mathrm{pH}$ 6.0) containing $5 \mathrm{mM}$ AgaDP3 and $1 \mathrm{mM}$ $\mathrm{MgCl}_{2}$ at $30^{\circ} \mathrm{C}$ and $200 \mathrm{rpm}$ for $2 \mathrm{~h}$. After terminating the enzymatic reactions by boiling the reaction samples for $3 \mathrm{~min}$, we determined the amount of galactose by HPLC. One unit of agarolytic $\beta$-galactosidase activity with regard to AgaDP3 was defined as the amount of enzyme required to produce $1 \mu$ mol of galactose per min under the reaction conditions described above. To investigate the crude enzyme reactions of $B$. infantis, we incubated a reaction mixture comprising the $2 \mathrm{mg} / \mathrm{mL}$ crude enzymes (i.e., cell-free extract or extracellular enzymes) and $2 \mathrm{mg} / \mathrm{mL}$ AgaDP3 in $20 \mathrm{mM}$ Tris $\mathrm{HCl}$ buffer ( $\mathrm{pH} \mathrm{7.0)}$ at $30^{\circ} \mathrm{C}$ and $200 \mathrm{rpm}$ for $2 \mathrm{~h}$. We used lactose as a positive control substrate for determining $\beta$-galactosidase activity. The agarolytic $\beta$-galactosidase activities of the crude enzymes and the recombinant enzymes belonging to $\mathrm{GH} 2$ from $B$. plebeius, the recombinant enzymes of BACPLE_01672, BACPLE_01673, and BACPLE_01706, were tested using the same method described above. 
LC/MS - IT - TOF analysis. We used an LC/MS - IT - TOF system (Shimadzu, Kyoto, Japan) equipped with a Hypercarb Porous Graphitic Carbon LC column $(100 \mathrm{~mm} \times 2.1 \mathrm{~mm}$, packed with $3-\mu \mathrm{m}$ particles; Thermo Fisher Scientific) to analyze the NAOSs and AOSs derived from the agarose ${ }^{50}$. During the analysis, the temperatures of the autosampler and LC column were maintained at $10{ }^{\circ} \mathrm{C}$ and $70{ }^{\circ} \mathrm{C}$, respectively. The mobile phase comprised two solutions- $25 \mu \mathrm{M}$ lithium chloride and acetonitrile-for gradient elution ranging from 0 to $80 \%$ at a flow rate of $0.2 \mathrm{~mL} / \mathrm{min}$ for $41 \mathrm{~min}$. Electrospray ionization was operated in a positive-ion mode. The source-dependent parameters were set as follows: nebulizing gas flow, $1.5 \mathrm{~L} / \mathrm{min}$; interface voltage, $4.5 \mathrm{kV}$; detector voltage, $1.65 \mathrm{kV}$; curved desolvation line temperature, $200^{\circ} \mathrm{C}$; and heat block temperature, $200{ }^{\circ} \mathrm{C}$. The mass scan range was $100-1200 \mathrm{~m} / z$. To obtain tandem mass data from the precursor ions, the collision-induced dissociation (CID) parameters-i.e., the CID energy, collision gas parameter, and frequency-were set at $50 \%$, $50 \%$, and $45 \mathrm{kHz}$, respectively. The raw data obtained from the LC/MS - IT - TOF analysis were processed using LabSolutions LCMS software (version 3.8; Shimadzu).

Gas chromatography-mass spectrometry analysis. To analyze AHG produced from cell culture or enzymatic reaction with agarose, gas chromatography-mass spectrometry (GC-MS) was used. The culture supernatant or reaction product was centrifuged at $25,200 \times \mathrm{g}$ for $10 \mathrm{~min}$ at $4{ }^{\circ} \mathrm{C}$, and $10 \mu \mathrm{L}$ of the supernatant was dried in a centrifugal vacuum evaporator. For chemical derivatization, we added $40 \mathrm{mg} / \mathrm{mL}$ methoxyamine hydrochloride in pyridine (Sigma-Aldrich) to the vacuum-dried sample, and incubated the mixture for $90 \mathrm{~min}$ at $30^{\circ} \mathrm{C}$. We then mixed each sample with $45 \mu \mathrm{L}$ of $N$-methyl- $N$-(trimethylsilyl)-trifluoroacetamide (MSTFA; Sigma-Aldrich), and incubated the mixture for $30 \mathrm{~min}$ at $37^{\circ} \mathrm{C}$. The derivatized samples were analyzed using an Agilent 7890A GC/5975C MSD system (Agilent Technologies, Wilmington, DE, USA) equipped with an RTX5Sil MS column $(30 \mathrm{~m} \times 0.25 \mathrm{~mm}$; film thickness, $0.25 \mu \mathrm{m})$ (Restek, Bellefonte, PA, USA) with a 10-m guard column. Each sample $(1 \mu \mathrm{L})$ was injected into the GC using the split mode with a split ratio of 2 . The oven program was as follows: an initial temperature of $50^{\circ} \mathrm{C}$ for $1 \mathrm{~min}$; heating to $330^{\circ} \mathrm{C}$ at $20^{\circ} \mathrm{C} / \mathrm{min}$; and maintenance of the temperature at $330^{\circ} \mathrm{C}$ for $5 \mathrm{~min}$. Electron ionization was performed at $70 \mathrm{eV}$, and the temperatures of the ion source and transfer line were $250{ }^{\circ} \mathrm{C}$ and $280^{\circ} \mathrm{C}$, respectively. The mass spectra of the samples were obtained in the mass range $85-500 \mathrm{~m} / \mathrm{z}$.

For the quantitative analyses of AgaDP3, NeoDP2, and AHG, an Agilent 7890A GC (Agilent Technologies) coupled with a Pegasus HT time-of-flight (TOF) - mass spectrometry (MS) (LECO, St. Joseph, MI) was used. Each sample $(1 \mu \mathrm{L})$ was injected into the GC using the split mode with a split ratio of 2 and separated on an RTX-5Sil MS column ( $30 \mathrm{~m} \times 0.25 \mathrm{~mm}$; film thickness, $0.25 \mu \mathrm{m})$ (Restek, Bellefonte, PA, USA) with a 10-m guard column. The oven program was as follows: an initial temperature of $50^{\circ} \mathrm{C}$ for $1 \mathrm{~min}$; heating to $330^{\circ} \mathrm{C}$ at $20^{\circ} \mathrm{C} /$ min; and maintenance of the temperature at $330^{\circ} \mathrm{C}$ for $5 \mathrm{~min}$. Electron ionization was performed at $70 \mathrm{eV}$, and the temperatures of the ion source and transfer line were $250{ }^{\circ} \mathrm{C}$ and $280^{\circ} \mathrm{C}$, respectively. The mass spectra of the samples were obtained in the mass range $85-500 \mathrm{~m} / \mathrm{z}$.

HPLC analysis. We used a HPLC system (1200 Series, Agilent Technologies) equipped with a $\mathrm{H}^{+}(8 \%)$ column (Rezex ROA-Organic Acid; Phenomenex, Torrance, CA, USA) and a refractive index (RI) detector for the HPLC analysis. The flow rate of the $0.005 \mathrm{~N} \mathrm{H}_{2} \mathrm{SO}_{4}$ mobile phase was set at $0.6 \mathrm{~mL} / \mathrm{min}$, and the column and refractive index detector temperatures were set at $50^{\circ} \mathrm{C}$.

TLC analysis. TLC analysis of the enzymatic reaction products was conducted on a silica gel 60 plate (Merck), and the plate was developed with an $n$-butanol-ethanol-water mixture $(3: 1: 1, \mathrm{v} / \mathrm{v} / \mathrm{v})$ for $1 \mathrm{~h}$. The plate was then dried and visualized using a solution comprising $10 \%(\mathrm{v} / \mathrm{v})$ sulfuric acid and $0.2 \%(\mathrm{w} / \mathrm{v}) 1,3$-dihydroxynaphthalene (Sigma-Aldrich) in ethanol at $90^{\circ} \mathrm{C}$ for $1 \mathrm{~min}$.

Accession numbers of recombinant enzymes. The NCBI accession numbers of the proteins analyzed in this study are the following: BpGH16A, WP_007560915.1; BpGH50, WP_007560940.1; BpGH117, WP_007560917.1; Bga2A, WP_012578561.1; Bga42A, WP_012578289.1; Bga42B, WP_012578388.1; Bga42C, WP_012578637.1.

\section{Data availability}

All data are available in the main text or the additional information.

Received: 14 January 2021; Accepted: 9 June 2021

Published online: 06 July 2021

\section{References}

1. Ndeh, D. et al. Complex pectin metabolism by gut bacteria reveals novel catalytic functions. Nature 544, 65-70 (2017).

2. Luis, A. S. et al. Dietary pectic glycans are degraded by coordinated enzyme pathways in human colonic Bacteroides. Nat. Microbiol. 3, 210-219 (2018).

3. Hehemann, J.-H. et al. Transfer of carbohydrate-active enzymes from marine bacteria to Japanese gut microbiota. Nature 464, 908-912 (2010).

4. Flint, H. J., Scott, K. P., Duncan, S. H., Louis, P. \& Forano, E. Microbial degradation of complex carbohydrates in the gut. Gut Microbes 3, 289-306 (2012).

5. Ley, R. E., Turnbaugh, P. J., Klein, S. \& Gordon, J. I. Microbial ecology: human gut microbes associated with obesity. Nature 444, 1022-1023 (2006).

6. Martens, E. C., Chiang, H. C. \& Gordon, J. I. Mucosal glycan foraging enhances fitness and transmission of a saccharolytic human gut bacterial symbiont. Cell Host Microbe 4, 447-457 (2008). 
7. Pickard, J. M. et al. Rapid fucosylation of intestinal epithelium sustains host-commensal symbiosis in sickness. Nature 514, 638-641 (2014).

8. Sonnenburg, E. D. et al. Specificity of polysaccharide use in intestinal Bacteroides species determines diet-induced microbiota alterations. Cell 141, 1241-1252 (2010).

9. D'Elia, J. N. \& Salyers, A. A. Effect of regulatory protein levels on utilization of starch by Bacteroides thetaiotaomicron. J. Bacteriol. 178, 7180-7186 (1996).

10. Brune, A. Symbiotic digestion of lignocellulose in termite guts. Nat. Rev. Microbiol. 12, 168-180 (2014).

11. Pluvinage, B. et al. Molecular basis of an agarose metabolic pathway acquired by a human intestinal symbiont. Nat. Commun. 9, 1043. https://doi.org/10.1038/s41467-018-03366-x (2018).

12. Thomas, F. et al. Characterization of the first alginolytic operons in a marine bacterium: from their emergence in marine Flavobacteriia to their independent transfers to marine Proteobacteria and human gut Bacteroides. Environ. Microbiol. 14, 2379-2394 (2012).

13. Yasui, A. Outline of standard tables of food composition in Japan-2015-(7th revised edition). Vol. 74 (2016).

14. Lee, H. J., Kim, H. C., Vitek, L. \& Nam, C. M. Algae consumption and risk of type 2 diabetes: Korean National Health and Nutrition Examination Survey in 2005. J. Nutr. Sci. Vitaminol. 56, 13-18 (2010).

15. Okubo, H. et al. Three major dietary patterns are all independently related to the risk of obesity among 3760 Japanese women aged 18-20 years. Int. J. Obes. 2005(32), 541-549 (2008).

16. Shimazu, T. et al. Dietary patterns and cardiovascular disease mortality in Japan: a prospective cohort study. Int. J. Epidemiol. 36, 600-609 (2007).

17. Wong, K. H., Sam, S. W., Cheung, P. C. K. \& Ang, P. O. Changes in lipid profiles of rats fed with seaweed-based diets. Nutr. Res. 19, 1519-1527 (1999).

18. Kim, N.-J., Li, H., Jung, K., Chang, H. N. \& Lee, P. C. Ethanol production from marine algal hydrolysates using Escherichia coli KO11. Bioresour. Technol. 102, 7466-7469 (2011).

19. Jang, S.-S., Shirai, Y., Uchida, M. \& Wakisaka, M. Production of mono sugar from acid hydrolysis of seaweed. Afr. J. Biotechnol. 11, 1953-1963 (2012).

20. Ale, M. T., Maruyama, H., Tamauchi, H., Mikkelsen, J. D. \& Meyer, A. S. Fucoidan from Sargassum sp. and Fucus vesiculosus reduces cell viability of lung carcinoma and melanoma cells in vitro and activates natural killer cells in mice in vivo. Int. J. Biol. Macromol. 49, 331-336 (2011).

21. Aisa, Y. et al. Fucoidan induces apoptosis of human HS-sultan cells accompanied by activation of caspase-3 and down-regulation of ERK Pathways. Am. J. Hematol. 78, 7-14 (2005).

22. Kim, E. J., Park, S. Y., Lee, J. Y. \& Park, J. H. Fucoidan present in brown algae induces apoptosis of human colon cancer cells. BMC Gastroenterol. 10, 96. https://doi.org/10.1186/1471-230x-10-96 (2010).

23. Zhang, Z., Teruya, K., Eto, H. \& Shirahata, S. Induction of apoptosis by low-molecular-weight fucoidan through calcium-and caspase-dependent mitochondrial pathways in MDA-MB-231 breast cancer cells. Biosci. Biotechnol. Biochem. 77, 235-242 (2013).

24. Yun, E. J. et al. Enzymatic production of 3,6-anhydro-L-galactose from agarose and its purification and in vitro skin whitening and anti-inflammatory activities. Appl. Microbiol. Biotechnol. 97, 2961-2970 (2013).

25. Hoshiyama, Y., Sekine, T. \& Sasaba, T. A case-control study of colorectal cancer and its relation to diet, cigarettes, and alcohol consumption in Saitama Prefecture Japan. Tohoku J. Exp. Med. 171, 153-165 (1993).

26. Hoshiyama, Y. \& Sasaba, T. A case-control study of stomach cancer and its relation to diet, cigarettes, and alcohol consumption in Saitama Prefecture Japan. Cancer Causes Control 3, 441-448 (1992).

27. Kato, I. et al. A comparative case-control study of colorectal cancer and adenoma. Jpn. J. Cancer Res. 81, 1101-1108 (1990).

28. Knutsen, S., Myslabodski, D., Larsen, B. \& Usov, A. I. A modified system of nomenclature for red algal galactans. Bot. Mar. 37, $163-170$ (1994).

29. Hehemann, J.-H., Kelly, A. G., Pudlo, N. A., Martens, E. C. \& Boraston, A. B. Bacteria of the human gut microbiome catabolize red seaweed glycans with carbohydrate-active enzyme updates from extrinsic microbes. Proc. Natl. Acad. Sci. U.S.A. 109, 19786-19791 (2012).

30. Duckworth, M. \& Turvey, J. R. The action of a bacterial agarase on agarose, porphyran and alkali-treated porphyran. Biochem. J. 113, 687-692 (1969).

31. Hehemann, J.-H., Smyth, L., Yadav, A., Vocadlo, D. J. \& Boraston, A. B. Analysis of keystone enzyme in agar hydrolysis provides insight into the degradation (of a polysaccharide from) red seaweeds. J. Biol. Chem. 287, 13985-13995 (2012).

32. Park, N. J., Yu, S., Kim, D. H., Yun, E. J. \& Kim, K. H. Characterization of BpGH16A of Bacteroides plebeius, a key enzyme initiating the depolymerization of agarose in the human gut. Appl. Microbiol. Biotechnol. 105, 617-625l (2021).

33. Giles, K., Pluvinage, B. \& Boraston, A. B. Structure of a glycoside hydrolase family 50 enzyme from a subfamily that is enriched in human gut microbiome bacteroidetes. Proteins 85, 182-187 (2017).

34. Yang, B. et al. Mechanism of mild acid hydrolysis of galactan polysaccharides with highly ordered disaccharide repeats leading to a complete series of exclusively odd-numbered oligosaccharides. FEBS J. 276, 2125-2137 (2009).

35. Higashimura, Y. et al. Protective effect of agaro-oligosaccharides on gut dysbiosis and colon tumorigenesis in high-fat diet-fed mice. Am. J. Physiol. Gastrointest. Liver Physiol. 310, G367-G375 (2016).

36. $\mathrm{Hu}, \mathrm{B}$. et al. Prebiotic effects of neoagaro-oligosaccharides prepared by enzymatic hydrolysis of agarose. Anaerobe 12, 260-266 (2006).

37. Li, M. M. et al. Isolation and characterization of an agaro-oligosaccharide (AO)-hydrolyzing bacterium from the gut microflora of Chinese individuals. PLoS ONE 9, e91106. https://doi.org/10.1371/journal.pone.0091106 (2014).

38. Garrido, D. et al. Utilization of galactooligosaccharides by Bifidobacterium longum subsp infantis isolates. Food Microbiol. 33, $262-270$ (2013).

39. Lee, C. H. et al. A novel agarolytic $\beta$-galactosidase acts on agarooligosaccharides for complete hydrolysis of agarose into monomers. Appl. Environ. Microbiol. 80, 5965-5973 (2014).

40. Yoshida, E. et al. Bifidobacterium longum subsp infantis uses two different $\beta$-galactosidases for selectively degrading type-1 and type-2 human milk oligosaccharides. Glycobiol. 22, 361-368 (2012).

41. Kavanaugh, D. W. et al. Exposure of Bifidobacterium longum subsp infantis to milk oligosaccharides increases adhesion to epithelial cells and induces a substantial transcriptional response. PLoS ONE 8, 67224. https://doi.org/10.1371/journal.pone.0067224 (2013).

42. Yun, E. J. et al. Promiscuous activities of heterologous enzymes lead to unintended metabolic rerouting in Saccharomyces cerevisiae engineered to assimilate various sugars from renewable biomass. Biotechnol. Biofuels 11, 140. https://doi.org/10.1186/s13068-0181135-7 (2018).

43. Yun, E. J. et al. In vitro prebiotic and anti-colon cancer activities of agar-derived sugars from red seaweeds. Mar. Drugs 19, 213. https://doi.org/10.3390/md19040213 (2021).

44. Turroni, F. et al. Diversity of bifidobacteria within the infant gut microbiota. PLoS ONE 7, 36957. https://doi.org/10.1371/journal. pone.0036957 (2012).

45. Garrido, D. et al. A novel gene cluster allows preferential utilization of fucosylated milk oligosaccharides in Bifidobacterium longum subsp longum SC596. Sci. Rep. 6, 35045. https://doi.org/10.1038/srep35045 (2016).

46. Shepherd, E. S., DeLoache, W. C., Pruss, K. M., Whitaker, W. R. \& Sonnenburg, J. L. An exclusive metabolic niche enables strain engraftment in the gut microbiota. Nature 557, 434-438 (2018). 
47. Kearney, S. M., Gibbons, S. M., Erdman, S. E. \& Alm, E. J. Orthogonal dietary niche enables reversible engraftment of a gut bacterial commensal. Cell Rep. 24, 1842-1851 (2018).

48. Barrangou, R., Altermann, E., Hutkins, R., Cano, R. \& Klaenhammer, T. R. Functional and comparative genomic analyses of an operon involved in fructooligosaccharide utilization by Lactobacillus acidophilus. Proc. Natl. Acad. Sci. U.S.A. 100, 8957-8962 (2003).

49. Yun, E. J. et al. Production of 3,6-anhydro-L-galactose from agarose by agarolytic enzymes of Saccharophagus degradans 2-40. Process Biochem. 46, 88-93 (2011).

50. Kim, J. H., Yun, E. J., Yu, S., Kim, K. H. \& Kang, N. J. Different levels of skin whitening activity among 3,6-anhydro-L-galactose, agarooligosaccharides, and neoagarooligosaccharides. Mar. drugs 15, 321. https://doi.org/10.3390/md15100321 (2017).

\section{Acknowledgements}

This work was supported by the Mid-career Researcher Program through the National Research Foundation of Korea (2020R1A2B5B02002631), by the Brain Pool Program through the Korean Federation of Science and Technology Societies funded by the Ministry of Science and ICT of Korea (2019H1D3A2A01100327), and by the Korea Institute of Planning and Evaluation for Technology in Food, Agriculture, Forestry, and Fisheries funded by the Ministry of Agriculture, Food, and Rural Affairs (321036051SB010). We also acknowledge the grant support by Korea University and the facility support by the Institute of Biomedical and Food Safety at CJ Food Safety Hall, Korea University.

\section{Author contributions}

K.H.K. and Y.S.J. conceived the project. K.H.K., Y.S.J., and E.J.Y. designed the experiments. E.J.Y., S.Y., N.J.P., Y.C., and N.R.H. performed the experiments. K.H.K., Y.S.J., and E.J.Y. analyzed the data. K.H.K, Y.S.J., E.J.Y, and S.Y. wrote the manuscript. All the authors read and approved the final manuscript.

\section{Competing interests}

K.H.K., Y.S.J., E.J.Y., S.Y., and N.J.P. have filed a patent on a part of this work. Y.C. and N.R.H declare that they have no competing interests.

\section{Additional information}

Supplementary Information The online version contains supplementary material available at https://doi.org/ 10.1038/s41598-021-92872-y.

Correspondence and requests for materials should be addressed to Y.-S.J. or K.H.K.

Reprints and permissions information is available at www.nature.com/reprints.

Publisher's note Springer Nature remains neutral with regard to jurisdictional claims in published maps and institutional affiliations.

(c) Open Access This article is licensed under a Creative Commons Attribution 4.0 International License, which permits use, sharing, adaptation, distribution and reproduction in any medium or format, as long as you give appropriate credit to the original author(s) and the source, provide a link to the Creative Commons licence, and indicate if changes were made. The images or other third party material in this article are included in the article's Creative Commons licence, unless indicated otherwise in a credit line to the material. If material is not included in the article's Creative Commons licence and your intended use is not permitted by statutory regulation or exceeds the permitted use, you will need to obtain permission directly from the copyright holder. To view a copy of this licence, visit http://creativecommons.org/licenses/by/4.0/.

(c) The Author(s) 2021 